\title{
Combined use of eddy covariance and sap flow techniques for partition of ET fluxes and water stress assessment in an irrigated olive orchard
}

\author{
C. Cammalleri ${ }^{a}$, G. Rallo ${ }^{\mathrm{b}, *}$, C. Agnese ${ }^{\mathrm{b}}$, G. Ciraolo $^{\mathrm{c}}$, M. Minacapilli $^{\mathrm{b}}$, G. Provenzano $^{\mathrm{b}}$ \\ a U.S. Department of Agriculture, Agricultural Research Service, Hydrology and Remote Sensing Laboratory, Beltsville, MD, USA \\ ${ }^{\mathrm{b}}$ Department of Agro-Environmental Systems (SAGA), Università degli Studi di Palermo, Viale delle Scienze Ed. 4, 90128, Palermo, Italy \\ ${ }^{\mathrm{c}}$ Department of Civil, Environmental and Aerospace Engineering (DICA), Università degli Studi di Palermo, Viale delle Scienze Ed. 8, 90128 Palermo, Italy
}

\section{A R T I C L E I N F O}

\section{Article history:}

Received 17 December 2011

Accepted 4 October 2012

Available online 3 November 2012

\section{Keywords:}

Eddy covariance

Sap flow

Flux partition

Water stress

Olive

\begin{abstract}
A B S T R A C T
Correct estimation of crop actual transpiration plays a key-role in precision irrigation scheduling, since crop growth and yield are associated to the water passing through the crop.

Objective of the work was to assess how the combined use of micro-meteorological techniques (eddy covariance, $E C$ ) and physiological measurements (sap flow, $S F$ ) allows a better comprehension of the processes involving in the Soil-Plant-Atmosphere continuum.

To this aim, an experimental dataset of actual evapotranspiration, plant transpiration, and soil water content measurements was collected in an olive orchard during the midseason phenological period of 2009 and 2010.

It was demonstrated that the joint use of $E C$ and $S F$ techniques is effective to evaluate the components of actual evapotranspiration in an olive orchard characterized by sparse vegetation and a significant fraction of exposed bare soil.

The availability of simultaneous soil water content measurements allowed to estimate the crop coefficients and to assess a simple crop water stress index, depending on actual transpiration that can be evaluated even in the absence of direct measurements of actual transpiration.

The crop coefficients experimentally determined resulted very similar to those previously evaluated; in particular, in the absence of water stress, a seasonal average value of about 0.65 was obtained for the "single" crop coefficient, whereas values of a 0.34 and 0.41 were observed under limited water availability in the root zone.

The comparison between the values of crop water stress index evaluated during the investigated periods evidenced systematically lower values (less crop water stress) in the first year compared to the second, according to the general trend of soil waters content in the root zone.

Further researches are however necessary to extent the experimental dataset to periods characterized by values of soil evaporation higher than those observed, in order to verify the crop coefficients even under different conditions than those investigated.
\end{abstract}

(C) 2012 Elsevier B.V. All rights reserved.

\section{Introduction}

In the last decade, observations of physical processes developing in the Soil-Plant-Atmosphere (SPA) continuum become fundamental for agricultural water management, especially in arid and semi-arid ecosystems (Noy-Meir, 1973), where water is a limiting factor of the production, and the application of precision irrigation represents an appropriate management strategy. The development of precision irrigation aimed to reduce irrigation plays a major role in Mediterranean countries, where the reduction of water

\footnotetext{
* Corresponding author. Tel.: +39 091 7028150; fax: +39 091484035

E-mail address: rallo.giovanni@gmail.com (G. Rallo).
}

availability in the last 20 years has been observed (UNEP/MAPPlanBleu, 2009).

At present, studies on the dynamic of trees transpiration $(T)$, field evapotranspiration (ET) and soil water content (SWC) in areas characterized by sparse drought-resistant crops like olives groves, represent one of the most appealing challenges of agro-hydrological researches. In this context, particular relevance assumes the partition of actual ET in crop transpiration $(T)$ and soil evaporation $(E)$, because only the first term is essentially related to the crop water requirement and stress condition (Jackson et al., 1981). This interest is enhanced by the large variability in both space and time of these two components (Kemp et al., 1997; Smith et al., 1995).

The assessment of actual olive evapotranspiration, ET, and its partitioning, can be achieved with different methodologies. 
Whole actual evapotranspiration is commonly obtained using micro-meteorological techniques, i.e. by measuring the total water vapor fluxes with the eddy covariance $(E C)$ technique, representing at present the best known and widely accepted methodology (Verstraeten et al., 2009).

The role of soil evaporation in sparse vegetated areas can be relevant, particularly when the fraction of exposed soil is predominant (Heilman et al., 1994; Savage et al., 2000). This means that under this condition, $E C$ technique could not be able to recognize the effective crop water use, because of the relatively high contribute of soil evaporation.

In general, to separate $E T$ in $T$ and $E$, additional measurements of $T$ or $E$ are requested. Approaches based on tracking stable isotope in the water vapor fluxes, have been recently proposed to detect the source of fluxes (soil or vegetation) at field scale (Ferretti et al., 2003; Wang et al., 2010; Williams et al., 2004).

Alternatively, measurements of soil evaporation or plant transpiration can be carried out with microlysimeter (Martìnez-Cob and Faci, 2010) and sap flow sensors (Rousseaux et al., 2009), respectively. The latter represents a commonly used technique to monitor the sole transpiration term at the scale of single plant. Considering that the temporal delay induced by the effect of tree capacitance can be assumed negligible at daily scale, the methodology allows reliable estimations of $T$ fluxes, aiming to derive variables that can be directly related to the plant water status. However, multiple sources of uncertainty could be detected when processing sap flow observations (Allen et al., 2011), including inaccuracy in detection trunk geometry and sap wood depth, significant effect of trunk capacitance (Motisi et al., 2012) and/or the wood response to probe implantation (Clearwater et al., 1999).

Up-scaling transpiration fluxes from plant to field scale is complicated by the spatial heterogeneity of vegetation characteristics (Schaeffer et al., 2000); it is therefore necessary to know cropspecific parameters like leaf area index or sapwood surface (Oishi et al., 2008; Soegaard and Boegh, 1995).

In the absence of direct measurements, separate evaluation of $E$ and $T$ fluxes can also be obtained with agro-hydrological models; in fact several surface-vegetation-atmosphere-transfer (SVAT) models allow to determine the temporal dynamic of $E$ and $T$ using various schematizations of the physical processes; these models however, require a high number of soil and crop parameters (Cammalleri et al., 2010a; Crow et al., 2008; Minacapilli et al., 2008, 2009; Rallo et al., 2012).

A simplified way to deal with actual ET components is the "dual approach" method suggested by Allen et al. (1998), in which soil evaporation and potential plant transpiration are estimated by multiplying reference evapotranspiration $E T_{0}$, respectively, to a soil evaporation coefficient $\left(K_{e}\right)$ and a basal crop coefficient $\left(K_{c b}\right)$. Despite this approach is affected by theoretical limitations, it can be considered acceptable for practical applications.

The main objective of the paper is to assess if the joint use of $E C$ and $S F$ techniques is effective to partition the whole actual evapotranspiration in $T$ and $E$, in an olive orchard characterized by sparse vegetation and a significant fraction of exposed bare soil. Moreover, under the examined environmental conditions, experimental values of crop coefficients, as defined by Allen et al. (1998), are determined. The dynamic of a crop water stress index (Jackson et al., 1981), evaluated according to measured actual transpiration, was finally investigated.

\section{Materials and methods}

\subsection{Site description}

The experimental study area, showed in Fig. 1, is mainly cultivated with olive orchard (cv. "Nocellara del Belice") and has an

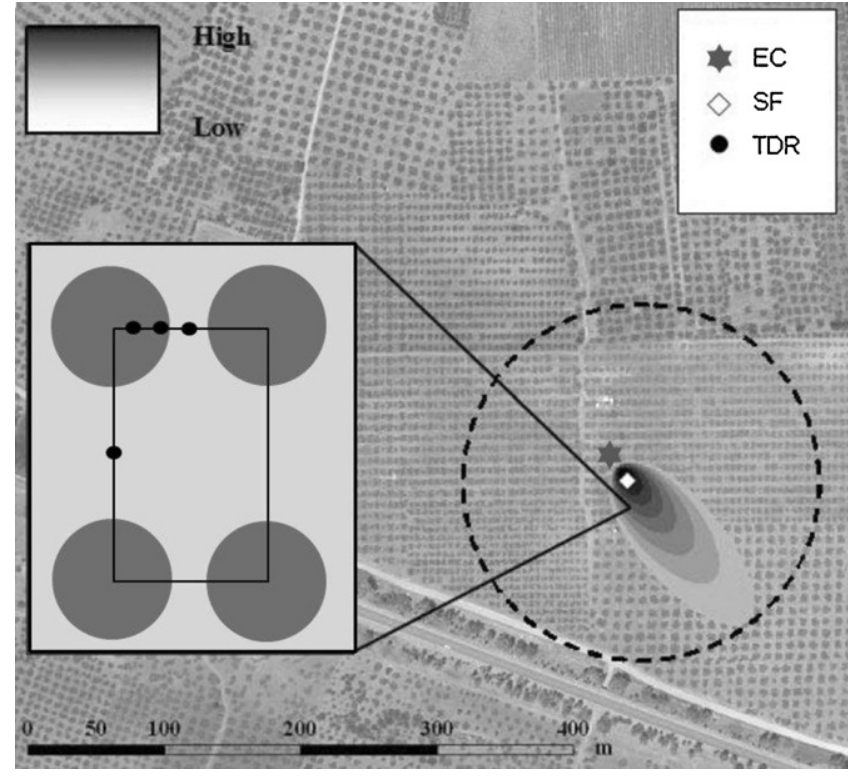

Fig. 1. Orthophoto of the experimental site, showing the location of eddy covariance system, $E C$, and sap flow sensors, $S F$; the filled area represents the footprint for the daytime predominant wind (average speed of $3.1 \mathrm{~m} \mathrm{~s}^{-1}$ with direction of $140^{\circ}$ ). The zoom emphasizes the locations of TDR probes.

extension of about 13 ha. The site is located in the South-West of Sicily (Italy), about $5 \mathrm{~km}$ far from the town of Castelvetrano (37.6494"N, 12.8492"E, $123 \mathrm{~m}$ a.s.1.) and it is characterized by a flat landscape and a rather homogeneous soil type.

Within the study field the plants, having a height of about $3.5 \mathrm{~m}$, are spaced according to a regular grid $5 \mathrm{~m} \times 8 \mathrm{~m}$ (density of 250 plants/ha); the average fraction cover is about 0.35 .

The climate of the area is typically Mediterranean, characterized by moderate rainfall during autumn and winter and quite high air temperatures and low precipitation in summer. Fig. 2 shows the daily and cumulative rainfall distributions registered, from June to December 2009 and 2010, by SIAS (Servizio Informativo Agrometeorologico Siciliano) in a meteorological station located about $500 \mathrm{~m}$ apart from the study area. The meteorological station also allows to monitor solar radiation, wind speed, air temperature and relative humidity.

Irrigation water is supplied by a drip irrigation system (four $81 \mathrm{~h}^{-1}$ emitter/plant). Irrigation volumes, decided by the farmer according to the ordinary management practiced in the area, resulted quite different in the 2 years, as detailed in Table 1 .

Traditional laboratory methods were used to evaluate soil hydraulic properties of undisturbed soil cores, representative of four different depths $(0,30,60$ and $100 \mathrm{~cm})$ of a soil profile. At each depth two soil samples $0.05 \mathrm{~m}$ height and $0.08 \mathrm{~m}$ diameter were collected in order to determine some points of the water retention curve, in the range of matric potential between -0.05 and $-153 \mathrm{~m}$. Hanging water column apparatus was used to evaluate soil water contents corresponding to matric potential values ranging from $-0.05 \mathrm{~m}$ to $-1.5 \mathrm{~m}$; pressure plate apparatus with sieved soil

Table 1

Irrigation volumes scheduled in 2009 and 2010.

\begin{tabular}{lllllll}
\hline Date & DOY & \multicolumn{2}{l}{2009} & & 2010 & \\
\cline { 3 - 4 } \cline { 6 - 7 } & & $\left(\mathrm{m}^{3} \mathrm{ha}^{-1}\right)$ & $(\mathrm{mm})^{\mathrm{a}}$ & & $\left(\mathrm{m}^{3} \mathrm{ha}^{-1}\right)$ & $(\mathrm{mm})^{\mathrm{a}}$ \\
\hline $25 / 07$ & 206 & - & - & 210 & 30 \\
$05 / 08$ & 217 & 210 & 30 & - & - \\
$20 / 08$ & 232 & 105 & 15 & - & - \\
\hline
\end{tabular}

a Irrigation depths have been computed considering a wetted fraction area of 0.7 . 


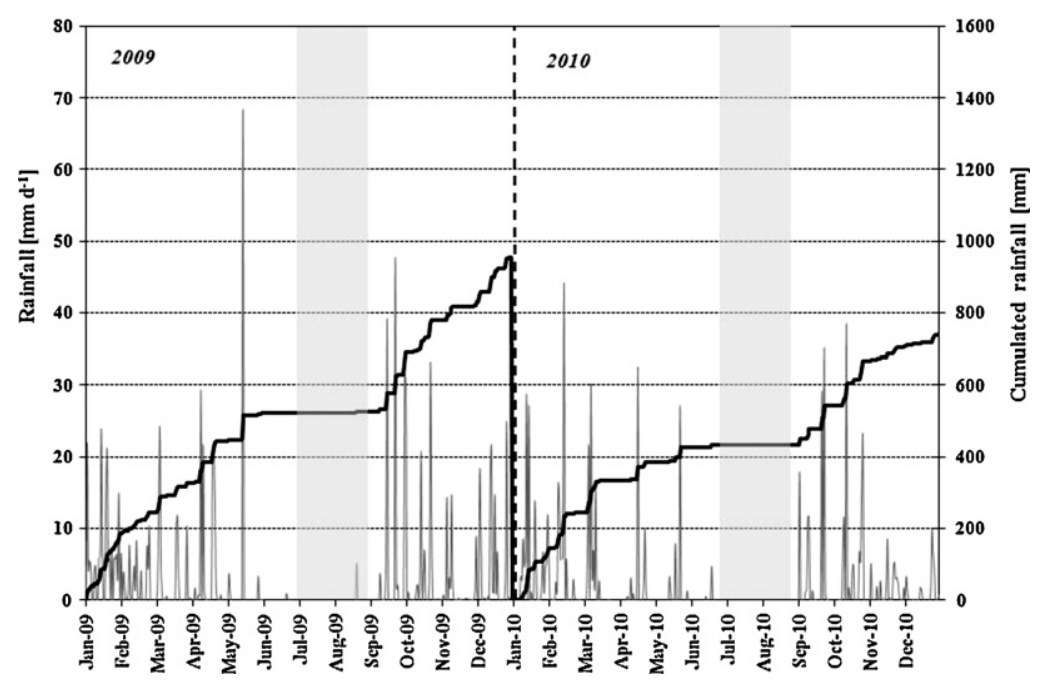

Fig. 2. Daily and cumulative rainfall distributions registered from June to December 2009 and 2010.

samples $0.05 \mathrm{~m}$ diameter and $0.01 \mathrm{~m}$ height, was used to measure soil water contents corresponding to soil matric potentials of $-3.37 \mathrm{~m},-10.2 \mathrm{~m},-30.6 \mathrm{~m}$ and $-153.0 \mathrm{~m}$. For each undisturbed soil sample, dry bulk density was also determined. Soil texture was measured by the hydrometer method. Soil textural class, according to USDA classification, is classified as silty clay loam; average clay, silt and sand contents resulted equal to 24,16 and $60 \%$, respectively.

The average water retention curve obtained along the soil profile was then used to determine soil water contents at field capacity, $S W C_{f c}$, and wilting point, $S W C_{w p}$, whose value resulted equal to $0.32 \mathrm{~m}^{3} \mathrm{~m}^{-3}$ and $0.08 \mathrm{~m}^{3} \mathrm{~m}^{-3}$.

\subsection{Micrometeorological fluxes measurements}

Energy balance and evapotranspiration measurements were performed using the eddy correlation (EC) method (Rosenberg et al., 1983; Kaimal and Finnigan, 1994; Stull, 1988) that is widely accepted as the reference methodology to observe the atmospheric turbulence in the surface boundary layer. Using $E C$, it is possible to derive the sensible heat flux, $H\left(\mathrm{~W} \mathrm{~m}^{-2}\right)$, as:

$H=\rho c_{p} \sigma_{w T}$

where $\rho\left(\mathrm{g} \mathrm{m}^{-3}\right)$ is the air density, $c_{p}\left(\mathrm{Jg}^{-1} \mathrm{~K}^{-1}\right)$ is the air specific heat capacity at constant pressure and $\sigma_{w T}\left(\mathrm{~ms}^{-1} \mathrm{~K}\right)$ is the covariance between vertical wind speed and air temperature.

Similarly, the vertical flux of water vapor content, i.e., the latent heat flux, $\lambda E T\left(\mathrm{~W} \mathrm{~m}^{-2}\right)$, can be expressed as:

$\lambda E T=\lambda \sigma_{w q}$

where $\lambda\left(\mathrm{Jg}^{-1}\right)$ is the latent heat of vaporization and $\sigma_{w q}\left(\mathrm{~g} \mathrm{~m}^{-2} \mathrm{~s}^{-1}\right)$ is the covariance between the vertical wind speed and the water vapor density.

The auxiliary experimental set-up is also constituted by net radiometer, to measure net radiation, $R_{n}$, and self-calibrated flux plates, to measure soil heat flux, $G_{0}$.

The energy balance closure can be tested considering the closure ratio, $C R$, evaluated as:

$C R=\frac{H+\lambda E T}{R_{n}-G_{0}}$

This ratio, as suggested by Prueger et al. (2005), has to be computed only from the subset of data for which $R_{n}$ is higher than $100 \mathrm{~W} \mathrm{~m}^{-2}$. For the following analysis, the surface balance closure was forced according to the procedure proposed by Twine et al.(2000), in order to keep constant the observed Bowen ratio between the sensible and latent heat fluxes.

In the center of the experimental area (Fig. 1) an $E C$ tower has been installed. The system allows to obtain high frequency measurements of the three wind components and the $\mathrm{H}_{2} \mathrm{O}$ and $\mathrm{CO}_{2}$ concentrations by means of a three dimensional sonic anemometer (CSAT3-3D, Campbell Scientific Inc.) and an infrared open-path gas analyzer (LI7500, Li-cor Biosciences Inc.), respectively. Both the instruments were installed at an elevation of $7 \mathrm{~m}$ above the ground; the sample frequency for the raw data was equal to $20 \mathrm{~Hz}$.

The auxiliary experimental set-up is represented by a low frequency (30-min), 4-components net radiometer (CNR-1 Kipp \& Zonen) located at an elevation of $8.5 \mathrm{~m}$ and two self-calibrated flux plates (HFP01SC, Hukseflux) placed, respectively, in the exposed and shadowed bare soil, at a depth of about $0.1 \mathrm{~m}$. All the data (high and low frequency) were stored in a CR5000 data logger (Campbell Scientific Inc.) equipped with a PCMCIA memory card.

EC footprint was computed with the model proposed by Kormann and Meixner (2000), based on the analytical solution of the two-dimensional advection-diffusion equation for nonneutral stratifications. Fig. 1 shows the footprint, represented by the source area encompassing the $90 \%$ of the observed fluxes, obtained using the daytime predominant wind conditions (average speed of $3.1 \mathrm{~m} \mathrm{~s}^{-1}$ and direction of $140^{\circ}$ ). Finally the 30-min fluxes data were aggregated at daily scale and latent heat fluxes, acquired in $\mathrm{W} \mathrm{m}{ }^{-2}$, were then transformed in actual evapotranspiration values, ET $\left(\mathrm{mm} \mathrm{d}^{-1}\right)$.

\subsection{Sap flow and soil water content measurements}

The heat dissipation technique, HDT (Granier, 1985) allows to obtain the sap velocity by measuring difference of temperature between a heated and an unheated needle inserted radially into the sap wood. Therefore, the probe measures the heat dissipation in the sapwood, increasing with the sap flow. When the sap velocity is minimal, the temperature difference $(\Delta \tau)$ between the two sensors is maximal $\left(\Delta \tau_{\max }\right)$; for practical purposes, $\Delta \tau_{\max }$ is assumed to correspond to the zero flow condition.

This approach allows the estimation of sap velocity, $v$ $(\mathrm{cm} \mathrm{min}-1)$, by using the empirical relationships proposed by Granier (1985):

$v=0.714\left(\frac{\Delta \tau_{\max }-\Delta \tau}{\Delta \tau}\right)^{1.231}$ 
Sap fluxes, $q\left(\mathrm{~cm}^{3} \mathrm{~min}^{-1}\right)$, can be evaluated multiplying the sap flow velocity for the cross-sectional area of conducting sapwood, $S$ $\left(\mathrm{cm}^{2}\right)$ :

$q=v S$

Hourly measurements of sap velocity were acquired on three olive trees by using, for each of them, two standard thermal dissipation probes (SFS2 TypM-M; UP GmbH) installed into the trunk, at a height of about $0.4 \mathrm{~m}$ from the ground level. According to the footprint analysis, the position of the trees was chosen inside the area where the "relative normalized contribution" to flux was estimated near to the maximum (Fig. 1). Moreover, the three plants were selected according to their trunk diameter, so that they can be considered representative of entire experimental plot.

In all the trees, both the sap flow probes were installed on the north side of the trunk and then insulated, to avoid the direct sun exposure.

At the end of the experiments, the sapwood area was determined by a colorimetric method, on a total of six wood carrots extracted with a Pressler gimlet on the same three trees, in between each couple of the sap flow needles. The conductive section was identified by adding methyl-orange to the carrot, in order to enhance the difference between the sapwood and the heartwood. Each image of colored wood carrot was then analyzed with software Image-Pro Plus 6.0 to recognize the sapwood depth.

Temporal variability of soil water content (SWC) was continuously monitored around the same trees where sap flow sensors were installed, by using a time domain reflectometry system (TDR100; Campbell Scientific Inc.). A number of 12 probes, $20 \mathrm{~cm}$ length, were installed along four soil profiles, to explore SWC in the layers $10-30,30-60$ and $50-80 \mathrm{~cm}$. Unfortunately it was not possible to install TDR probes in the evaporative layer, due to the incoherent topsoil $(0-10 \mathrm{~cm})$. The planimetric position of the sensors, showed in Fig. 1, was chosen in order to consider the spatial variability of SWC after irrigation. Acquisition time step was set up to $3 \mathrm{~h}$ in the period from June to September of each year.

The data acquired by each probe were then aggregated to a daily time scale and the arithmetic mean value for the entire root zone was finally evaluated.

\subsection{Data analysis and pre-processing}

For both the monitored years, the micro-meteorological data and the measurements of plant and soil water status were pre-processed in order to create a daily database of reference evapotranspiration, $E T_{0}$, actual evapotranspiration, $E T$, plant transpiration, $T$, and soil water content, SWC.

For each of the 2 years (2009 and 2010) it was possible to dispose of a significant dataset of simultaneous measurements of $E C$, $T$ and SWC during the midseason phenological period (from the first decade of June, corresponding to the "initial fruit development" stage to the first decade of September, corresponding to the "maturity" stage) for a total of $90 \mathrm{~d}$.

The meteorological data collected by SIAS were used as an auxiliary independent information to estimate the atmospheric evaporative demand in the study area. Reference crop evapotranspiration, $E T_{0}\left(\mathrm{~mm} \mathrm{~d}^{-1}\right)$, was determined according to the FAO-56 procedure (Allen et al., 1998), on the basis of the following Penman-Monteith equation:

$E T_{0}=\frac{0.408 \Delta\left(R_{n}-G\right)+\gamma\left(900 / T_{a}+273\right)\left(U_{2}\left(e_{s}-e_{a}\right)\right)}{\Delta+\gamma\left(1+0,34 U_{2}\right)}$

where $\Delta\left[\mathrm{kPa}^{\circ} \mathrm{C}^{-1}\right]$ is the slope of saturation vapor pressure curve, $e_{S}(T)[\mathrm{KPa}]$ is the saturation vapor pressure at air temperature, $R_{n}$ $\left[\mathrm{MJ} \mathrm{m}{ }^{-2} \mathrm{~d}^{-1}\right]$ is the net radiation, $G\left[\mathrm{MJ} \mathrm{m}^{-2} \mathrm{~d}^{-1}\right]$ is the soil heat flux, $\left(e_{s}-e_{a}\right)[\mathrm{kPa}]$ is the vapor pressure deficit, $\gamma\left[\mathrm{kPa}{ }^{\circ} \mathrm{C}^{-1}\right]$ is the psychometric constant at air temperature $T_{a}\left[{ }^{\circ} \mathrm{C}\right]$ and $U_{2}\left[\mathrm{~m} \mathrm{~s}^{-1}\right]$ is the wind speed measured at $2 \mathrm{~m}$ from the soil surface.

EC measurements were pre-processed and the accuracy of balance closure was verified considering the closure ratio, $C R$ evaluated with Eq. (3), that resulted equal to 0.90 and 0.92 , respectively, for 2009 and 2010, as can be observed in Fig. 3.

Sap fluxes, $q\left(\mathrm{~cm}^{3} \mathrm{~min}^{-1}\right)$, computed by Eq. (5), allowed to determine the daily volume of water consumed by a single plant assuming negligible, at the daily time interval, the effect of the tree capacitance (Motisi et al., 2012). The daily stand transpiration of a plant, $T_{\text {plant }}$, can thus be evaluated dividing this water volume for the plant pertinence area, $A_{p}$ equal to $40 \mathrm{~m}^{2}$. In order to evaluate a representative value of the stand transpiration referred to the entire field, $T$, it was necessary to up-scale $T_{\text {plant }}$, by considering, as a proximal variable, the ratio between the average Leaf Area Index, $L A I\left(\mathrm{~m}^{2} \mathrm{~m}^{-2}\right)$, measured in field, and the corresponding value obtained on the single plant, $L A I_{p}\left(\mathrm{~m}^{2} \mathrm{~m}^{-2}\right)$, in which sap fluxes were monitored:

$T=T_{\text {plant }} \frac{L A I}{L A I_{p}}$

The values of $L A I$ and $L A I_{p}$ were estimated from in situ observations, collected with a hand-held optic sensor (Villalobos et al., 1995) even
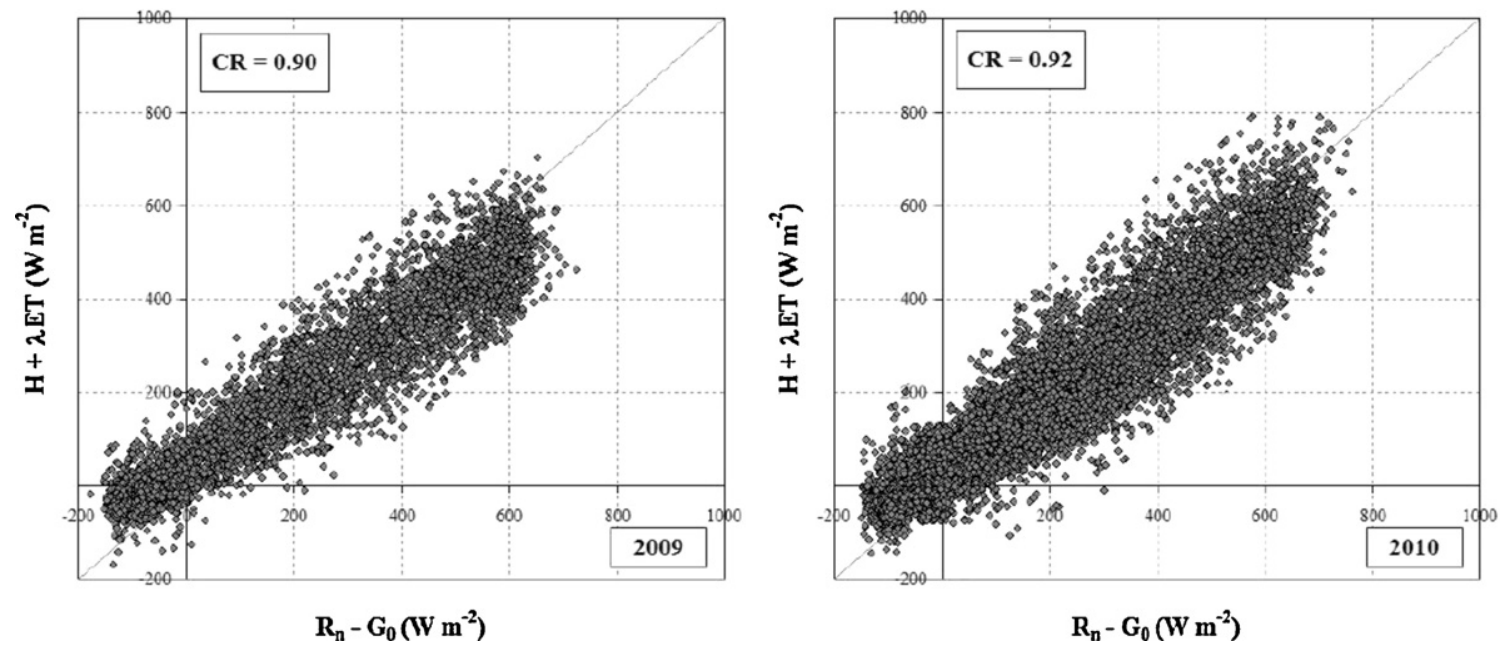

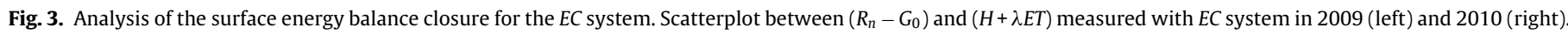
Values of the Closure Ratio, $C R$, are also indicated. 
if it has been recently demonstrated that, in the absence of direct measurements, high resolution remote sensing images can be used (Cammalleri et al., 2010b). For the examined conditions LAI resulted about to 0.89 , whereas $L A I_{p}$ was about 1.27 .

Crop coefficients were evaluated according to the FAO-56 procedure (Allen et al., 1998), in which actual evapotranspiration, ET, can be evaluated as:

$E T=T+E=\left(K_{c b} K_{s}+K_{e}\right) E T_{0}=K_{c, a d j} E T_{0}$

where $K_{c b}$ is the basal crop coefficient obtained when the soil surface is dry, but transpiration occurs at potential rate, $K_{S}$ is a dimensionless stress coefficient dependent on SWC and $K_{e}$ describes the evaporation component from wet soil, following rain or irrigation (Allen and Pereira, 2009). The sum $K_{c b} K_{s}+K_{e}$ represents the so called "dual" crop coefficient, $K_{c, a d j}$.

According to the FAO-56 procedure, $K_{S}$ has been computed as:

$K_{s}=\frac{T A W-D_{i}}{T A W-R A W}$ for $D_{i}>R A W$

$K_{S}=1$ for $D_{i} \leq R A W$

where $T A W(\mathrm{~mm})$ is the total available water, $D_{i}(\mathrm{~mm})$ is the amount of daily water depleted out from root zone during the $i$ th day, and $R A W(\mathrm{~mm})$ is the readily available water. The latter can be evaluated as a fraction, $p$, of TAW. As indicated in FAO-56 procedure, $p$ can be determined as:

$p=p_{\text {table }}+0.04\left(5-E T_{0}\right)$

Values of $p_{\text {table }}$ for different crops are suggested by Allen et al. (1998). For the investigated case, $p_{\text {table }}$ was set equal to 0.6 .

The evaporation coefficient, $K_{e}$, can be also derived following the procedure described in Allen et al. (1998), requiring, however, to measure soil water contents in the topsoil.

When water stress is absent, $\left(K_{S}=1\right)$, and soil evaporation is negligible, $K_{c b}+K_{e}$ returns to the standard crop coefficient $K_{c}$, as described in the "single" approach (Doorenbos and Pruitt, 1977; Allen et al., 1998), commonly used to compute the potential evapotranspiration, $E T_{p}$, as:

$E T_{p}=K_{c} E T_{0}$

Although values of $K_{c}$ and $K_{c b}$ for some crops can be found in the literature (Allen and Pereira, 2009) a correct estimation of these coefficients requires a local evaluation based on direct measurements.

In this study $K_{c b}$ and $K_{s}$ coefficients were obtained combining the experimental measurements of $E T$ and $T$ with the values of soil water content in the root zone, $S W C_{r}$. The stress factor $K_{s}$ was computed from Eq. (9), in which:

$D_{i}=1000 \times\left(S W C_{f c}-S W C_{r, i}\right) \times Z_{r}$

$T A W=1000 \times\left(S W C_{f c}-S W C_{w p}\right) \times Z_{r}$

Using the measurements of transpiration, $T$, once evaluated $K_{s}$, the experimental values of $K_{c b}$ were computed as:

$K_{c b}=\frac{T}{K_{s} E T_{0}}$

Due to the absence of $S W C$ measurements in the topsoil $(0-10 \mathrm{~cm})$ the experimental evaluation of $K_{e}$ was not possible; thus $K_{e}$ was derived from Eq. (8) as a residual term:

$K_{e}=\frac{E T-T}{E T_{0}}$

Then the "single" crop coefficient was computed as:

$K_{c}=K_{c b}+K_{e}$
Finally, the crop water stress condition during the investigated periods was described according to a crop water stress index, CWSI (Jackson et al., 1981) determined as:

$C W S I=1-\frac{T}{T_{p}}=1-\frac{T}{K_{c b} E T_{0}}$

\section{Results and discussion}

For each investigated period, the temporal dynamic of collected data was preliminarily analyzed in order to detect the main differences between the single components of the whole evapotranspiration fluxes.

For the 2009 season, Fig. 4a shows the temporal dynamic of evapotranspiration $E T$, plant transpiration, $T$, soil evaporation, $E$, as well as atmospheric demand, $E T_{0}$, rainfall, $P$ and the amount of irrigation, $I$. For the same period, Fig. $4 \mathrm{~b}$ shows the average soil water content in the root zone $\left(S W C_{r}, 30-100 \mathrm{~cm}\right)$ and in the upper soil layer $\left(S W C_{u}, 10-30 \mathrm{~cm}\right)$.

In the absence of direct measurements of surface soil evaporation and under the hypothesis to consider negligible the daily tree capacitance (Motisi et al., 2012), the term E, was estimated as difference between $E T$ and $T$ measurements.

The analysis of Fig. 4 evidences an average seasonal value of $T$ of $2.3 \mathrm{~mm} \mathrm{~d}^{-1}$; similar values were obtained by Rousseaux et al. (2009), during summer season, for an olive grove characterized by a canopy cover of $23 \%$.

A detailed analysis of Fig. 4 evidences that ET and $T$ fluxes tendencially decrease from beginning of June (initial fruit development stage) to September (maturity stage), according to the general trends of reference evapotranspiration and soil water contents.

High values of $E T$ (from 3 to $4 \mathrm{~mm} \mathrm{~d}^{-1}$ ) and $T$ (from 2 to $3 \mathrm{~mm} \mathrm{~d}^{-1}$ ) were in fact observed during the period between DOY 160 (second decade of June) and DOY 170 , when soil water contents in the root zone $\left(S W C_{r}\right)$ and in the upper layer $\left(S W C_{u}\right)$ were, on average, 0.22 and 0.10 , respectively; during the initial period, even soil evaporation, $E$, resulted high, with pick values greater than $1 \mathrm{~mm} \mathrm{~d}^{-1}$. This circumstance is in agreement to the high $S W C_{u}$ values, despite these data were collected in the layer $10-30 \mathrm{~cm}$ and not in the topsoil $(0-10 \mathrm{~cm})$.

After the second decade of June (DOY 180-210) ET values resulted slightly higher than $T$ and the consequent low soil evaporation (about $0.4 \mathrm{~mm} \mathrm{~d}^{-1}$ ) is supported by the low $S W C_{u}$ (about $0.05 \mathrm{~m}^{3} \mathrm{~m}^{-3}$ ). In the following period (DOY 210-230), the lack of EC measurements did not allow to evaluate soil evaporation, so that only a general reduction of $T$ can be observed.

A relevant contribution of soil evaporation can be detected after DOY $233\left(E=1.33 \mathrm{~mm} \mathrm{~d}^{-1}\right)$, due to the rainfall event, wetting the entire extension of the topsoil surface. Furthermore, the limited irrigation volume did not produce any significant effect in $S W C_{r}$ and accordingly the dynamic of crop transpiration did not change.

Table 2, for each decades of the considered period, shows the mean values of $S W C, K_{s}, E T_{0}, E T, T, E$, as well as crop coefficients $K_{c b}$, $K_{e}, K_{c}$ and $K_{c, a d j}$ and finally $T / E T_{0}, E / E T_{0}$ and $T / T_{p}$ ratios.

The average values of decadal crop coefficients, as well as $T / E T_{0}$ and $E / E T_{0}$ ratios, cannot be directly related to a single factor, depending on the combined effects of $E T_{0}$ and $S W C$.

Moreover, similarly to what described by Rousseaux et al. (2009), decadal values of $T / E T_{0}$ and $E / E T_{0}$ show low variability as evidenced by the corresponding values of the standard deviations. On the contrary a high variability of the $T / T_{p}$ ratio can be observed.

The average seasonal crop coefficients resulted very similar to those suggested by Allen et al. (1998) and also experimentally determined by Villalobos et al. (2000) and Testi et al. (2004), with seasonal actual transpiration equal to $34 \%$ of reference evapotranspiration. 

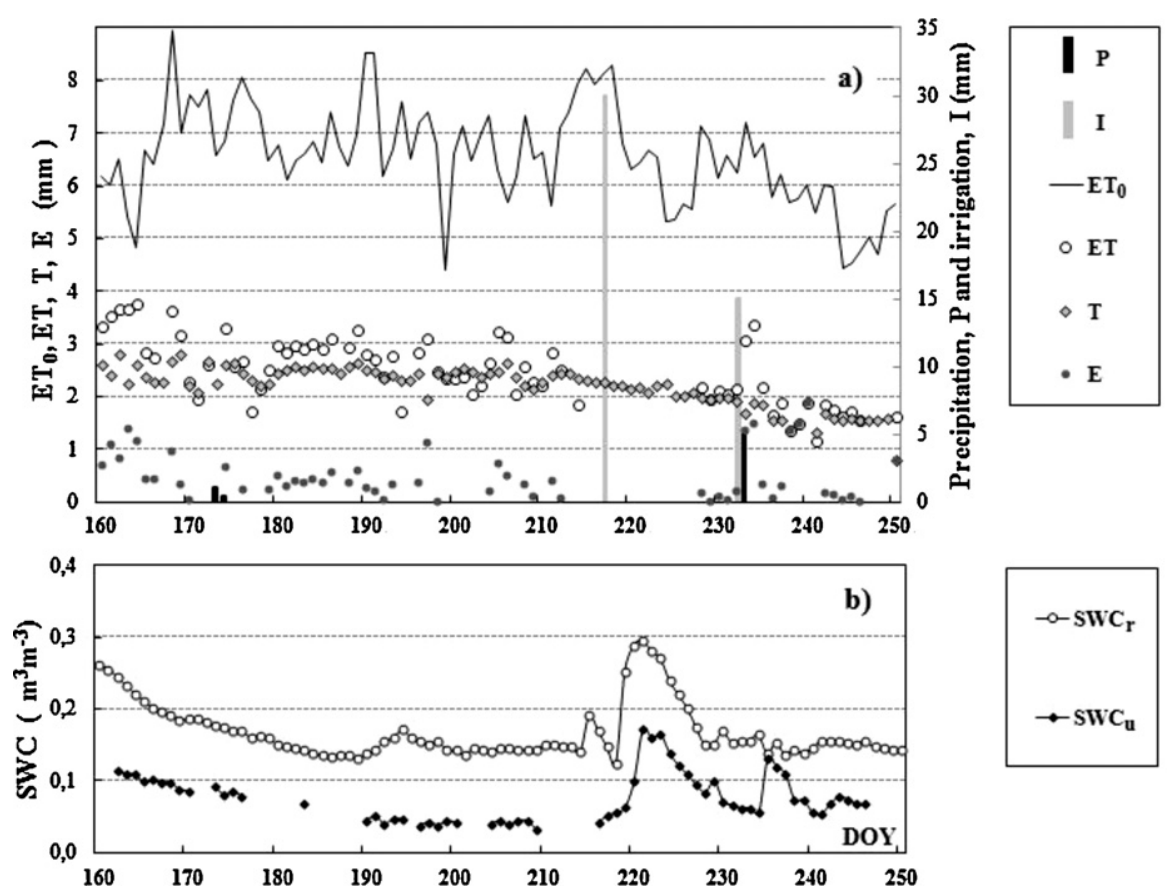

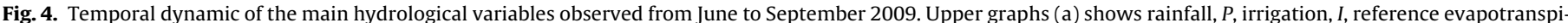

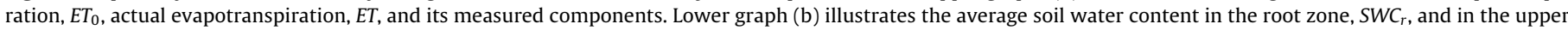
soil layer, $S W C_{u}$.

The same data analysis was replied for 2010, as shown in Fig. 5. As can be observed, measured $E T$ and $T$ fluxes tend to decrease from the begin (June) to the end (September) of the observation period, even if all fluxes resulted lower than those evaluated in 2009.

Average values of $E T \approx 3 \mathrm{mmd}^{-1}$ and $T \approx 2 \mathrm{mmd}^{-1}$ were observed between DOY 160 and DOY 170, when the average soil water content in the root zone $\left(S W C_{r}\right)$ and in the upper surface $\left(S W C_{u}\right)$ were approximately $0.16 \mathrm{~m}^{3} \mathrm{~m}^{-3}$ and $0.11 \mathrm{~m}^{3} \mathrm{~m}^{-3}$, respectively. In the following period (DOY 180-235) ET values resulted generally slightly higher than $T$ and the consequent low soil evaporation (about $0.3 \mathrm{~mm} \mathrm{~d}^{-1}$ ) is confirmed by values of $S W C_{u}$ of about $0.08 \mathrm{~m}^{3} \mathrm{~m}^{-3}$. Despite the irrigation volume $(30 \mathrm{~mm})$ in DOY 206 increased $S W C_{r}$, no significant influence on $E T$ an $T$ was observed, probably due to the limited atmospheric water demand during the days after irrigation.

In the following period (DOY 235-245) even if $T$ values decrease with the same tendency previously observed, actual evapotranspiration tends to increase as a consequence of the high atmospheric demand $\left(E T_{0} \approx 7 \mathrm{~mm} \mathrm{~d}^{-1}\right.$ ) from DOY 236 to DOY 240 .

Finally, after the rainfall event recorded during DOY 245, a significantly higher soil evaporation can be detected.
The decadal mean values of $S W C, K_{S}, E T_{0}, E T, T, E$, as well as crop coefficients $K_{c b}, K_{e}, K_{c}$ and $K_{c, a d j}, T / E T_{0}, E / E T_{0}$ and $T / T_{p}$ obtained for 2010 are summarized in Table 3. As can be observed, even in 2010 the values of $K_{e}, K_{c}$ and $K_{c b}$ resulted very similar to those evaluated in 2009.

On the contrary, in 2010 the decadal transpiration values resulted significantly lower than 2009 and strongly dependent on the $K_{S}$ stress coefficients evaluated according to the soil depletion (Fig. 6).

For the investigated crop, this circumstance suggests that when the availability of soil water content decreases under a threshold value $\left(\approx 0.16 \mathrm{~m}^{3} \mathrm{~m}^{-3}\right.$ ) for a long period, the plant transpiration is driven by only the SWC in the root zone. The seasonal average value of $T / E T_{0}$ obtained in 2010 shows that the transpiration was on average equal to $27 \%$ of reference evapotranspiration.

Finally, as observed for 2009 the seasonal crop coefficients, computed as averages over the entire period, resulted very similar to those suggested by Allen et al. (1998) and confirmed by Villalobos et al. (2000) and Testi et al. (2004). Particularly the average value of $K_{c b}, K_{e}$ and $K_{c}$ resulted not significantly different during both the considered years. The experiments confirmed that "seasonal"

Table 2

Mean values of the main hydrological variables, including plant and soil components of actual evapotranspiration and crop coefficients observed in 2009

\begin{tabular}{|c|c|c|c|c|c|c|c|c|c|c|c|c|c|c|c|}
\hline \multicolumn{2}{|l|}{ DOY } & \multirow[t]{2}{*}{$S W C_{r}\left(\mathrm{~m}^{3} \mathrm{~m}^{-3}\right)$} & \multirow[t]{2}{*}{$S W C_{S}$} & \multirow[t]{2}{*}{$K_{s}$} & \multirow[t]{2}{*}{$E T_{0}\left(\mathrm{mmd}^{-1}\right)$} & \multirow[t]{2}{*}{$E T\left(\mathrm{mmd}^{-1}\right)$} & \multirow[t]{2}{*}{$T\left(\mathrm{~mm} \mathrm{~d}^{-1}\right)$} & \multirow[t]{2}{*}{$E\left(\mathrm{mmd}^{-1}\right)$} & \multirow[t]{2}{*}{$K_{c}$} & \multirow[t]{2}{*}{$K_{c b}$} & \multirow[t]{2}{*}{$K_{e}$} & \multirow[t]{2}{*}{$K_{c, a d j}$} & \multirow[t]{2}{*}{$T / E T_{0}$} & \multirow[t]{2}{*}{$E / E T_{0}$} & \multirow[t]{2}{*}{$T / T_{p}$} \\
\hline Start & End & & & & & & & & & & & & & & \\
\hline 160 & 170 & 0.22 & 0.10 & 0.95 & 6.63 & 3.25 & 2.50 & 0.75 & 0.54 & 0.41 & 0.12 & 0.52 & 0.39 & 0.12 & 0.70 \\
\hline 171 & 180 & 0.17 & 0.08 & 0.65 & 7.27 & 2.83 & 2.40 & 0.43 & 0.60 & 0.54 & 0.06 & 0.40 & 0.35 & 0.06 & 0.55 \\
\hline 181 & 190 & 0.14 & 0.05 & 0.44 & 6.86 & 2.98 & 2.56 & 0.42 & 0.94 & 0.87 & 0.06 & 0.44 & 0.38 & 0.06 & 0.40 \\
\hline 191 & 200 & 0.15 & 0.04 & 0.58 & 6.79 & 2.73 & 2.37 & 0.36 & 0.65 & 0.60 & 0.05 & 0.38 & 0.33 & 0.05 & 0.54 \\
\hline 201 & 210 & 0.14 & 0.04 & 0.49 & 6.66 & 2.80 & 2.42 & 0.38 & 0.80 & 0.74 & 0.06 & 0.43 & 0.37 & 0.06 & 0.45 \\
\hline 211 & 220 & 0.18 & 0.10 & 0.56 & 7.38 & - & 2.33 & - & - & 0.69 & - & - & 0.39 & - & - \\
\hline 221 & 230 & 0.22 & 0.09 & 0.61 & 6.17 & - & 2.09 & - & - & 0.49 & - & - & 0.30 & - & - \\
\hline 231 & 240 & 0.15 & 0.08 & 0.57 & 6.28 & 2.66 & 1.79 & 0.87 & 0.58 & 0.50 & 0.08 & 0.36 & 0.28 & 0.08 & 0.49 \\
\hline 241 & 250 & 0.15 & 0.07 & 0.65 & 5.22 & 1.72 & 1.49 & 0.23 & 0.48 & 0.43 & 0.04 & 0.33 & 0.29 & 0.04 & 0.60 \\
\hline \multicolumn{4}{|c|}{ Seasonal average } & 0.61 & & & & & 0.65 & 0.59 & 0.06 & 0.41 & 0.34 & 0.07 & 0.53 \\
\hline \multicolumn{4}{|c|}{ Standard deviation } & 0.14 & & & & & 0.16 & 0.15 & 0.03 & 0.06 & 0.04 & 0.03 & 0.10 \\
\hline
\end{tabular}




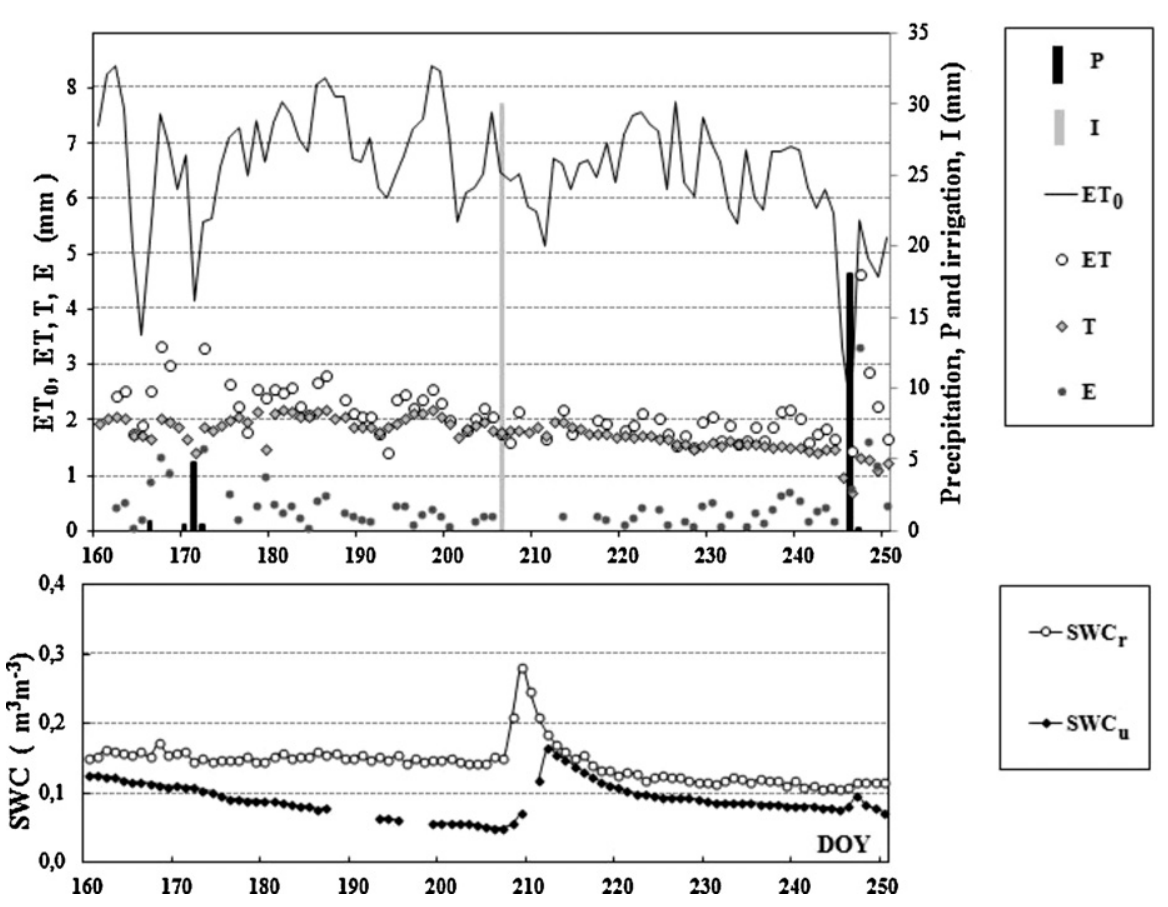

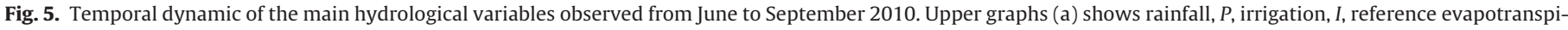

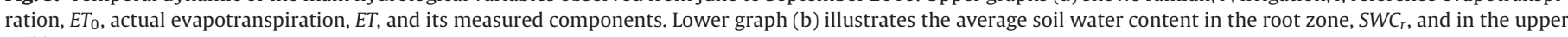
soil layer, $S W C_{u}$.

$K_{c}$ coefficients for the investigated crop can be assumed equal to 0.65 , as proposed by Allen et al. (1998).

Moreover it is interesting to notice that again the ratio $T / T_{p}$ at decadal scale is more variable than $T / E T_{0}$ and $E / E T_{0}$ values as a consequence of the higher variability of $K_{s}$. For this reason the crop water stress descriptor was chosen dependent on $T / T_{p}$.

Fig. 7a and b shows the temporal dynamic of $C W S I$ and soil water content in the root zone, $S W C_{r}$ in 2009 and 2010.

The comparison between the values of CWSI obtained during the investigated periods evidences generally lower values (less water stress) in the first year compared to the second, with seasonal average values of 0.32 and 0.53 for 2009 and 2010, respectively.

Differences of CWSI can be justified by the different soil water contents in the root zone, $S W C_{r}$, particularly in the first decade of June (DOY 160-170) and after the second decade of August (DOY 220-230).

The absence of water stress (CWSI $=0$ ), evident at the beginning of June 2009 , is certainly consequent to the high cumulative rainfall observed during 2 months antecedent the investigated period (see Fig. 2), producing a significant water storage in the soil.
Differently, in 2010 the lower cumulative rainfall antecedent the observation period and the consequent lower $S W C_{r}$ compared to 2009, determined conditions of crop water stress (CWSI >0) since the beginning of the investigated period. The higher initial water availability seems to reflect the minor extension of crop water stress observed in 2009 compared to 2010.

In the absence of measurements of actual transpiration, a simplified crop water stress index, CSWI*, can be evaluated after substituting in Eq. (18) the values of actual transpiration, $T^{*}$, indirectly estimated as $K_{c b} K_{s} E T_{0}$, obtaining:

$\mathrm{CWSI}^{*}=1-K_{S}$

Eq. (19) requires only the knowledge of $K_{S}$ that can be estimated as a function the soil water depletion $D_{i}$. According to Eq. (8), $D_{i}$ can be obtained from direct measurements of SWC or by following the simplified soil water balance approach proposed in the FAO-56 procedure.

Fig. 8 shows the comparison between the decadal values of CSWI and CSWI* for both the considered years. As can be observed the decadal indexes evaluated with measured actual transpirations

Table 3

Mean values of the main hydrological variables, including plant and soil components of actual evapotranspiration and crop coefficients observed in 2010.

\begin{tabular}{|c|c|c|c|c|c|c|c|c|c|c|c|c|c|c|c|}
\hline \multicolumn{2}{|l|}{ DOY } & \multirow[t]{2}{*}{$S W C_{r}\left(\mathrm{~m}^{3} \mathrm{~m}^{-3}\right)$} & \multirow[t]{2}{*}{$S W C_{s}$} & \multirow[t]{2}{*}{$K_{s}$} & \multirow[t]{2}{*}{$E T_{0}\left(\mathrm{~mm} \mathrm{~d}^{-1}\right)$} & \multirow[t]{2}{*}{$E T\left(\mathrm{~mm} \mathrm{~d}^{-1}\right)$} & \multirow[t]{2}{*}{$T\left(\mathrm{~mm} \mathrm{~d}^{-1}\right)$} & \multirow[t]{2}{*}{$E\left(\mathrm{~mm} \mathrm{~d}^{-1}\right)$} & \multirow[t]{2}{*}{$K_{c}$} & \multirow[t]{2}{*}{$K_{c b}$} & \multirow[t]{2}{*}{$K_{e}$} & \multirow[t]{2}{*}{$K_{c, a d j}$} & \multirow[t]{2}{*}{$T / E T_{0}$} & \multirow[t]{2}{*}{$E / E T_{0}$} & \multirow[t]{2}{*}{$T / T_{p}$} \\
\hline Start & End & & & & & & & & & & & & & & \\
\hline 160 & 170 & 0.16 & 0.11 & 0.64 & 6.66 & 2.48 & 1.87 & 0.61 & 0.58 & 0.49 & 0.09 & 0.40 & 0.29 & 0.09 & 0.57 \\
\hline 171 & 180 & 0.15 & 0.09 & 0.55 & 6.42 & 2.54 & 1.86 & 0.69 & 0.61 & 0.51 & 0.11 & 0.39 & 0.29 & 0.11 & 0.57 \\
\hline 181 & 190 & 0.15 & 0.08 & 0.61 & 7.46 & 2.37 & 2.05 & 0.32 & 0.50 & 0.46 & 0.04 & 0.32 & 0.28 & 0.04 & 0.60 \\
\hline 191 & 200 & 0.15 & 0.06 & 0.55 & 7.12 & 2.24 & 1.98 & 0.25 & 0.54 & 0.51 & 0.04 & 0.31 & 0.28 & 0.04 & 0.55 \\
\hline 201 & 210 & 0.18 & 0.09 & 0.52 & 6.28 & 2.02 & 1.81 & 0.21 & 0.58 & 0.55 & 0.03 & 0.31 & 0.29 & 0.03 & 0.53 \\
\hline 211 & 220 & 0.16 & 0.12 & 0.55 & 6.48 & 1.98 & 1.79 & 0.19 & 0.53 & 0.50 & 0.03 & 0.29 & 0.28 & 0.03 & 0.55 \\
\hline 221 & 230 & 0.12 & 0.09 & 0.43 & 7.04 & 1.88 & 1.60 & 0.28 & 0.62 & 0.58 & 0.04 & 0.27 & 0.23 & 0.04 & 0.39 \\
\hline 231 & 240 & 0.12 & 0.08 & 0.37 & 6.43 & 1.86 & 1.53 & 0.34 & 0.71 & 0.66 & 0.05 & 0.29 & 0.24 & 0.05 & 0.36 \\
\hline 241 & 250 & 0.11 & 0.08 & 0.29 & 4.99 & 2.14 & 1.22 & 0.91 & 1.11 & 0.92 & 0.19 & 0.44 & 0.25 & 0.19 & 0.27 \\
\hline \multicolumn{4}{|c|}{ Seasonal average } & 0.50 & & & & & 0.64 & 0.58 & 0.07 & 0.34 & 0.27 & 0.07 & 0.49 \\
\hline \multicolumn{4}{|c|}{ Standard deviation } & 0.11 & & & & & 0.19 & 0.14 & 0.05 & 0.06 & 0.02 & 0.05 & 0.12 \\
\hline
\end{tabular}




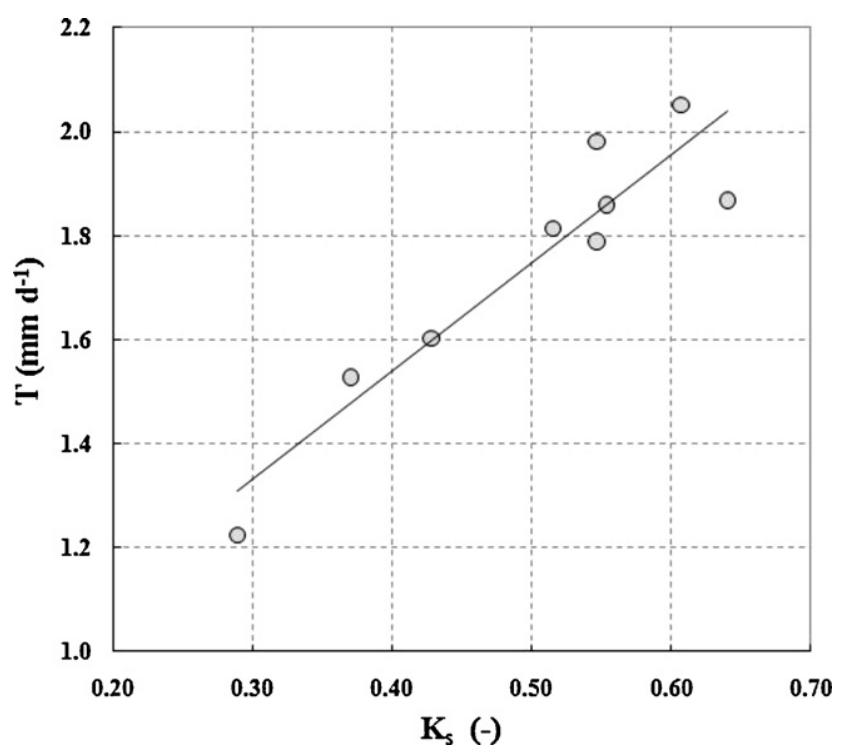

Fig. 6. Scatterplot between decadal measured actual transpiration, $T$, and crop stress coefficient, $K_{s}$, observed during 2010.

(Eq. 18) resulted very similar to those calculated according to $K_{S}$ (Eq. 19). In the absence of direct measurements of actual transpiration, a suitable stress descriptor can be therefore evaluated from measured or estimated values of soil water content in the root zone.

\section{Conclusions}

The research assessed how the joint measurements of eddy covariance and sap flow techniques allow a better comprehension of the combined roles of actual crop transpiration and soil evaporation in a typical Mediterranean olive orchard, where the problem of evapotranspiration fluxes partitioning is quite complex.

An experimental dataset of ET and T measurements, collected from June to September 2009 and 2010, has been analyzed. In the absence of direct measurements of soil evaporation, the ET and $T$ measurements, coupled with simultaneous measurements of soil water contents, ensured the correct partition of evapotranspiration fluxes.

In both the investigated years $E T$ and $T$ fluxes resulted very similar during dry periods, due to the negligible contribute of soil evaporation; on the other hands the differences became relevant only for a few days after rainfall events. ET fluxes measured in 2009 resulted generally higher than those recognized in 2010, as a consequence of higher SWC observed in 2009. Moreover, the different soil water status between the 2 years evidenced that when the availability of soil water content decreases under a threshold value $\left(\approx 0.16 \mathrm{~m}^{3} \mathrm{~m}^{-3}\right)$ for a long period, the plant transpiration is only driven by the soil water content.

The experimental dataset allowed to assess decadal values of crop coefficients evaluated according to the "single" and the "dual" approaches suggested by the FAO-56 procedure. Average seasonal crop coefficients resulted practically the same in both the investigated years and similar to those suggested by other authors.

The temporal dynamic of CWSI, computed using direct measurements of $T$, was analyzed and the observed differences during the

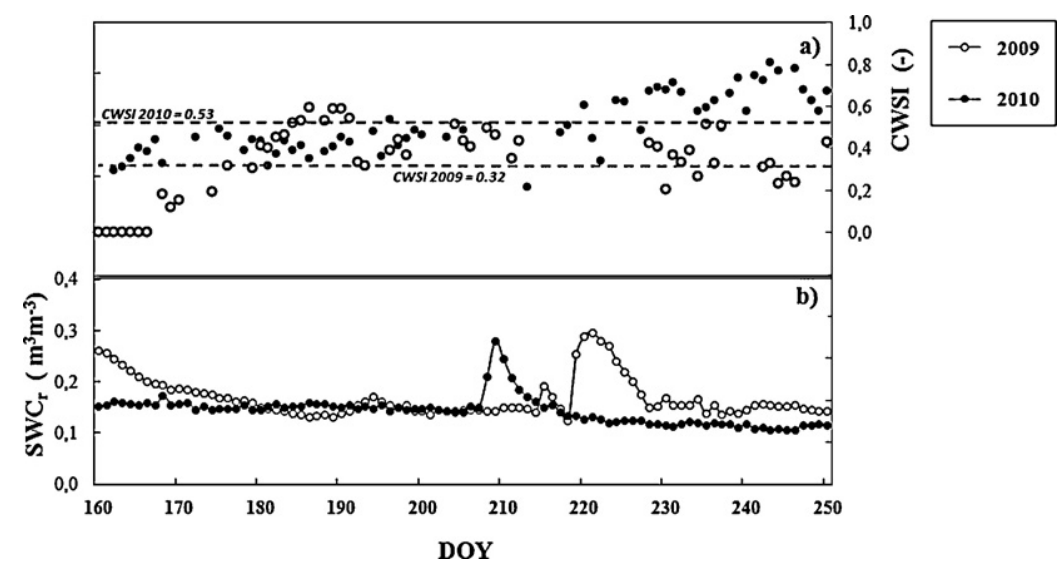

Fig. 7. Temporal dynamic of crop water stress index, CWSI, and soil water content in the root zone, $S W C_{r}$ obtained in 2009 and 2010.
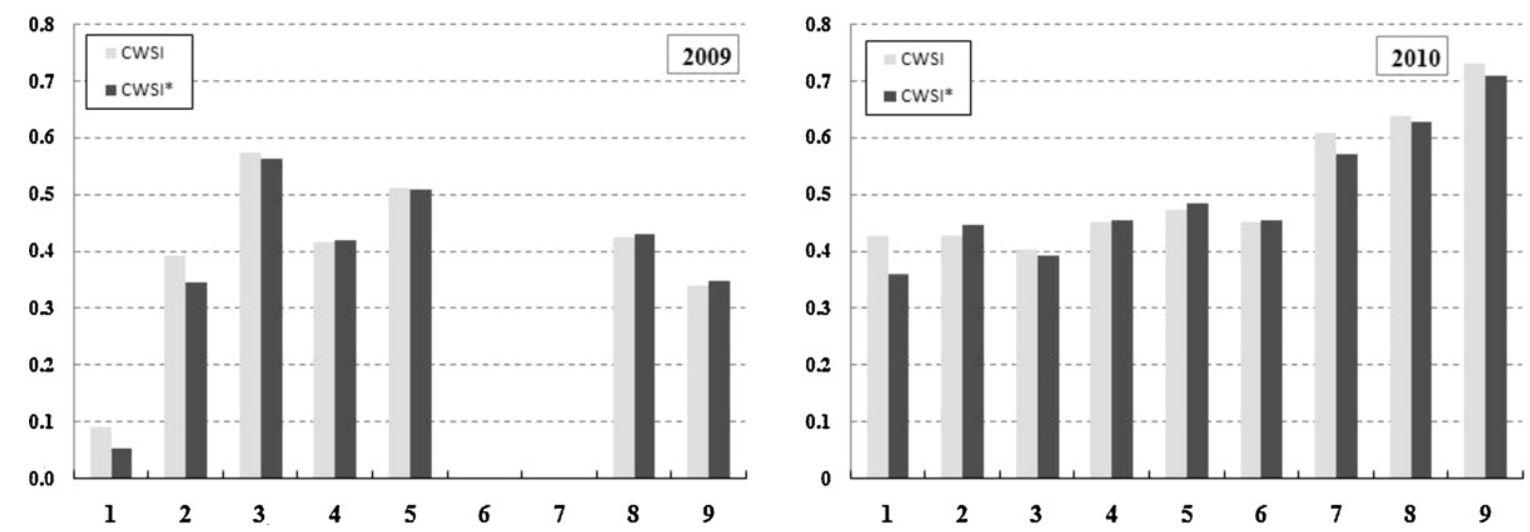

Fig. 8. Comparison between decadal CWSI and $C W S I^{*}$ values for both years. 
examined periods were related to the soil water content in the root zone. In fact, the systematically lower values of CWSI (less water stress) in the first year reflect the corresponding generally higher soil water content in the root zone.

Finally, the decadal values of the simplified crop water stress index obtained with measured soil depletion, resulted quite similar to those derived from $T$ measurements, demonstrating that, at this temporal scale, a suitable stress descriptor can be obtained using parameters derived by measured or estimated soil water contents.

Further experiments will be carried out in order to extent the experimental dataset to periods characterized by high values of soil evaporation, in order to verify the crop coefficients under different conditions than those investigated.

\section{Acknowledgments}

Contribution to the paper has to be shared between Authors as following: Field data collection and pre-processing were cared by G. Rallo and C. Cammalleri. All the authors equally contributed to set-up the research, process the data and write the paper.

The authors wish to thank the farm "Tenuta Rocchetta - by Angela Consiglio" for kindly hosting the experimental setup. The research was funded by the DIFA project of the Sicilian Regional Government and PRIN 2008 (Provenzano) co-financed by Ministero dell'Istruzione, dell'Università e della Ricerca (MIUR) and by Università degli Studi di Palermo.

\section{References}

Allen, R.G., Pereira, L.S., Raes, D., Smith, M., 1998. Crop evapotranspiration, guideline for computing crop water requirements. FAO Irrigation and Drainage Paper No. 56 , Rome, Italy, $326 \mathrm{pp}$

Allen, R.G., Pereira, L.S., 2009. Estimating crop coefficients from fraction of ground cover and height. Irrigation Science 28, 17-34.

Allen, R.G., Pereira, L.S., Howell, T.A., Jensen, M.E., 2011. Evapotranspiration information reporting: I. Factors governing measurement accuracy. Agricultural Water Management 98 (6), 899-920.

Cammalleri, C., Agnese, C., Ciraolo, G., Minacapilli, M., Provenzano, G., Rallo, G., 2010a. Actual evapotranspiration assessment by means of a coupled energy/hydrologic balance model: validation over an olive grove by means of scintillometry and measurements of soil water contents. Journal of Hydrology $392(1-2), 70-82$.

Cammalleri, C., Anderson, M.C., Ciraolo, G., D’Urso, G., Kustas, W.P., La Loggia, G., Minacapilli, M., 2010b. The impact of in-canopy wind profile formulations on heat flux estimation in an open orchard using the remote sensing-based twosource model. Hydrology and Earth System Sciences 14 (12), 2643-2659.

Clearwater, M.J., Meinzer, F.C., Andrade, J.L., Goldstein, G., Holbrook, N.M., 1999. Potential errors in measurement of nonuniform sap flow using heat dissipation probes. Tree Physiology 19, 681-687.

Crow, W.T., Kustas, W.P., Prueger, J.H., 2008. Monitoring root-zone soil moisture through the assimilation of a thermal remote sensing-based soil moisture proxy into a water balance model. Remote Sensing of Environment 112, 1268-1281.

Doorenbos, J., Pruitt, W.O., 1977. Crop water requirements. FAO Irrigation and Drainage Paper 24, United Nation Food and Agriculture Organization, Rome.

Ferretti, D.F., Pendall, E., Morgan, J.A., Nelson, J.A., Le Cain, D., Mosier, A.R., 2003. Partitioning evapotranspiration fluxes from a Colorado grassland using stable isotopes: seasonal variations and ecosystem implications of elevated atmospheric $\mathrm{CO}_{2}$. Plant Soil 254, 291-303.

Granier, A., 1985. Une nouvelle méthode pour la mesure du flux de sève brute dans le tronc des arbres. Annales des Sciences Forestieres 42, 193-200.

Heilman, J.L., McInnes, K.J., Savage, M.J., Gesch, R.W., Lascano, R.J., 1994. Soil and canopy energy balances in a west Texas vineyard. Agricultural and Forest Meteorology 71, 99-114.

Jackson, R.D., Idso, S.B., Reginato, R.J., Pinter, J.P.J., 1981. Canopy temperature as a drought stress indicator. Water Resources Research 17, 1133-1138.
Kaimal, J.C., Finnigan, J.J., 1994. Atmospheric Boundary Layer Flows. Oxford University Press, New York, USA, 289 pp.

Kemp, P.R., Reynolds, J.F., Pachepsky, Y., Chen, J., 1997. A comparative modeling study of soil water dynamics in a desert ecosystem. Water Resources Research 33, 73-90.

Kormann, R., Meixner, F.X., 2000. An analytical footprint model for non-neutral stratification. Boundary-Layer Meteorology 99, 207-224.

Martìnez-Cob, A., Faci, J.M., 2010. Evapotranspiration of an hedge-pruned olive orchard in a semiarid area of NE Spain. Agricultural Water Management 97, 410-418.

Minacapilli, M., Iovino, M., D‘Urso, G., 2008. A distributed agro-hydrological model for irrigation water demand assessment. Agricultural Water Management 95, 123-132.

Minacapilli, M., Iovino, M., Blanda, F., 2009. High resolution remote estimation of soil surface water content by a thermal inertia approach. Journal of Hydrology 379 (3-4), 229-238.

Motisi, A., Rossi, F., Consoli, S., Papa, R., Minacapilli, M., Rallo, G., Cammalleri, C., D‘Urso, G., 2012. Eddy covariance and sap flow measurements of energy and mass exchanges of woody crops in a Mediterranean environment. Acta Horticulturae (ISHS) 951, 121-127.

Noy-Meir, I., 1973. Desert ecosystems: environment and producers. Annual Review of Ecology, Evolution, and Systematics 4, 51-58.

Oishi, A.C., Oren, R., Stoy, P.C., 2008. Estimating components of forest evapotranspiration: a footprint approach for scaling sap flux measurements. Agricultural and Forest Meteorology 148, 1719-1732.

Prueger, J.H., Hatfield, J.L., Kustas, W.P., Hipps, L.E., MacPherson, J.I., Parkin, T.B., 2005. Tower and aircraft eddy covariance measurements of water vapor, energy and carbon dioxide fluxes during SMACEX. Journal of Hydrometeorology 6, 954-960.

Rallo, G., Agnese, C., Minacapilli, M., Provenzano, G., 2012. Comparison of SWAP and FAO agro-hydrological models to schedule irrigation of wine grapes. Journal of Irrigation and Drainage Engineering 138 (7), 581-591.

Rosenberg, N.J., Blad, B.L., Verma, S.B., 1983. Microclimate. The Biological Environment. Wiley, New York, USA, pp. 255-257.

Rousseaux, M.C., Figuerola, P.I., Correa-Tedesco, G., Searles, P.S., 2009. Seasonal variations in sap flow and soil evaporation in an olive (Olea europaea L.) grove under two irrigation regimes in an arid region of Argentina. Agricultural Water Management 96, 1037-1044.

Savage, M.J., Graham, A.D.N., Lightbody, K.E., 2000. An investigation of the stem steady state heat energy balance technique in determining water use by trees. Water Res. Comm. Report No. 348/1/00, 181 pp.

Schaeffer, S.M., Williams, D.G., Goodrich, D.C., 2000. Transpiration in cottonwood/willow forest patches estimated from sap flux. Agricultural and Forest Meteorology 105, 257-270.

Smith, S.D., Herr, C.A., Leary, K.L., Piorkowsky, J.M., 1995. Soil-plant water relations in a Mojave desert mixed shrub community: a comparison of three geomorphic surfaces. Journal of Arid Environments 29, 339-351.

Soegaard, H., Boegh, E., 1995. Estimation of evapotranspiration from a millet crop in the Sahel combining sap flow, leaf area index and eddy correlation technique. Journal of Hydrology 166, 265-282.

Stull, R.B., 1988. An Introduction to Boundary Layer Meteorology. Kluwer Academic Publishers, Dordrecht, 666 pp.

Testi, L., Villalobos, F.J., Orgaz, F., 2004. Evapotranspiration of a young irrigated olive orchard in southern Spain. Agricultural Water Management 121, 1-18.

Twine, T.E., Kustas, W.P., Norman, J.M., Cook, D.R., Houser, P.R., Meyers, T.P., Prueger, J.H., Starks, P.J., Wesely, M.L., 2000. Correcting eddy-covariance flux underestimates over a grassland. Agricultural and Forest Meteorology 103 (3), 279-300.

UNEP/MAP-PlanBleu, 2009. State of the Environmental Development in the Mediterranean. UNEP/MAP-PlanBleu, Athens, Greece, 204 pp.

Verstraeten, W.W., Veroustraete, F., Feyen, J., 2009. Assessment of evapotranspiration and soil moisture content across different scales of observation. Sensors 8 , 70-117.

Villalobos, F.J., Orgaz, F., Mateos, L., 1995. Non-destructive measurements of leaf area index in olive (Olea europaea L.) trees using a gap inversion method. Agricultural and Forest Meteorology 73, 29-42.

Villalobos, F.J., Orgaz, F., Testi, L., Fereres, E., 2000. Measurement and modelling evapotranspiration of olive (Olea europaea L.) orchards. European Journal of Agronomy 13, 155-163.

Wang, L., Caylor, K.K., Villegas, J.C., Barron-Gafford, G.A., Breshears, D.D., Huxman, T.E., 2010. Partitioning evapotranspiration across gradients of woody plant cover: assessment of a stable isotope technique. Geophysical Research Letters 37, L09401.

Williams, D.G., Cable, W., Hultine, H., Hoedjes, J.C.B., Yepez, E.A., Simonneaux, V., Er-Raki, S., Boulet, G., de Bruin, H.A.R., Chehbouni, A., Hartogensis, O.K., Timouk, F., 2004. Evapotranspiration components determined by stable isotope, sap flow and eddy covariance techniques. Agricultural and Forest Meteorology 125, 241-258. 